\title{
Training of volunteers for social services as an element of a participatory model of sustainable development paradigm
}

\author{
Ekaterina Ogorodnikova*, Andrey Plakhin, and Konstantin Rostovtsev \\ Ural State University of Economics, 8 Marta Str, 62, 620144 Ekaterinburg, Russia
}

\begin{abstract}
The relevance of the study of the processes of training volunteers working in social service organizations is due to the massive use of labor of non-professional participants to provide social services to needy groups of the population. The purpose of this article is to substantiate a conceptual model for organizing regional systems for vocational training and certification of volunteers in the field of social services. The research was carried out on the basis of studying, summarizing and systematizing scientific literature, regulatory documents, training programs for volunteers, and social service standards. As a method of empirical research, a survey of 54 volunteers in the field of social services was used, which revealed the main issues of training for the subsequent provision of services in the field of social services. A review of theoretical sources identified the characteristics of two approaches to training social service volunteers. The first assumes a hierarchical model with a gradual expansion of a volunteer functions, depending on the training programs completed with the receipt of a attestation certificate. The second model involves the training of volunteers directly at the sites of providing social services with the involvement of students from specialized universities. Empirical research has shown that in Russia, in most cases, the training of volunteers in the field of social services is carried out by specialists from institutions in which volunteer activities are carried out in the form of short-term seminars and an oral survey on the presented material. Consequently, it can be stated that there are no fullfledged systems of professional training and certification of volunteers in the field of social services, the construction methodology of which is considered in the works of a number of foreign authors. The formation of such a system in Russia should become one of the target priorities for the development of the volunteer movement, since the specificity of the problems of social services requires special knowledge, skills and abilities.
\end{abstract}

\section{Introduction}

The Federal Law of the Russian Federation No. 135 of 11.08.1995 "On Charitable Activities and Volunteering" states that a volunteer is an individual who performs work and services for social benefit without compensation, and, as indicated in Article 2 of this Law one of the main goals of volunteering is social support and protection of citizens, including social

\footnotetext{
*Corresponding author: cmb_8@mail.ru
} 
rehabilitation of the unemployed, disabled people and other persons. The implementation of the goals of volunteering often requires special knowledge and skills. Volunteers need special competencies in the provision of psychological and pedagogical services, organization of leisure time, career guidance work, valeological, patriotic and socio-legal counseling. In this regard, the training of volunteers is interpreted in the context of this study as training volunteers in a complex of functions and tasks of volunteering, the formation of knowledge, skills and abilities necessary for this activity.

It is important to emphasize that during the 2020 coronavirus pandemic, the demand for the services of social service volunteers has sharply increased, since the circle of consumers of these services has expanded many times over. The category of people in need of daily help from volunteers includes numerous groups of the population, including citizens over 65 years of age, people with chronic diseases, people with confirmed coronavirus infection and living with the infected.

As noted in the work of Deslandes M., Rogers L. A [1] "... well-trained volunteers are more important for successful work with disadvantaged groups than any other single factor." A number of researchers are considering the motivational consequences of training volunteers to provide social services. The article by Wilson J. [2] presents the results of a study confirming the positive effect of training on the propensity to volunteer and the growth of motivation for the reasons of increasing awareness of social problems, increasing empathy and satisfaction from self-development in helping those in need. The growth of the quality of social services and the expansion of social interaction as a result of the training of volunteers is noted by Herzog A. R. [3]. The results of a study presented in the article by Barkan S. E., Cohn S. F., Whitaker W. H. [4] indicate that training has a positive effect on reducing the emotional burnout of volunteers: highly educated people are not only more inclined to volunteer, but also less likely to drop out of the volunteer process.

An overview of the content components of volunteer training programs in the field of social services reveals the following main blocks:

- skills of rendering assistance depending on the direction of rendering social services, in this case the training programs should be differentiated depending on the peculiarities of the situation in which the beneficiaries find themselves. Fundamental works by Hardcastle D.A., Powers P.R., Wenocur S. [5], Cameron C., Moss P. [6], Seden J. [7], devoted to the general principles and methods of developing this component, are adapted to practical implementation, taking into account state standards provision of social services;

- attraction and adaptation of new participants in the volunteer movement, this block should be associated with such issues as mentoring, teamwork, interaction with professional staff of social institutions [8-10];

- psychological and communication skills of volunteers, allowing to consider the issues of counteracting emotional burnout [11-13];

- organization and management of volunteer activities, this block should include the legal framework for organizing volunteer activities, network management within non-profit organizations, as well as project management mechanisms [14, 15].

\section{Methods}

The research was carried out on the basis of a study of regulations, volunteer training programs, and social service standards. As a method of empirical research, a survey of 54 volunteers in the field of social services was used, highlighting the following main issues of training for the provision of social services:

- content components of training programs;

- forms and duration of classes;

- ways of checking competencies. 
The survey participants carry out systematic volunteer activities in social service organizations: Rehabilitation center for children and adolescents with disabilities "Talisman" (Yekaterinburg, RF), Regional center for the rehabilitation of disabled people (Yekaterinburg, RF), Social rehabilitation center for minors No. 1 "Rainbow" (Nizhny Tagil, RF). It should be noted that the work of volunteers has been used in these social service institutions for more than 10 years, including actively involved volunteers from the student environment. Among the universities of active participants in the volunteer movement, the Ural State University of Economics and the Russian State Vocational Pedagogical University are mentioned, which is associated with the professional specifics of the training areas of these universities.

\section{Results}

Figure 1 shows the results of the distribution of survey participants by training forms.

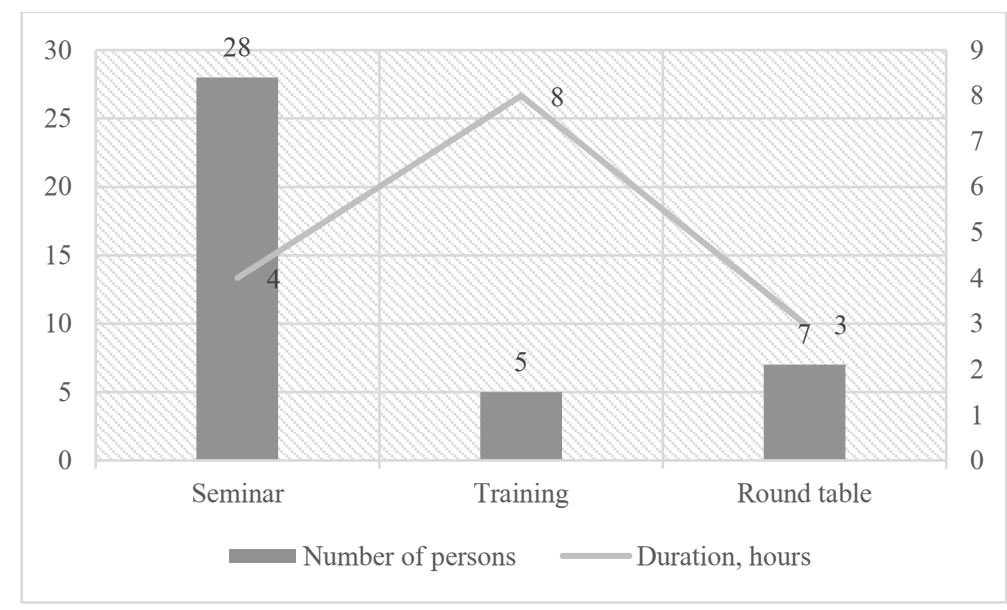

Fig. 1. Distribution of survey participants by training forms, number of people

Most often, training of volunteers in the field of social services is carried out in the form of introductory seminars in small groups. As the survey results show 28 people have passed such training, the average duration of a lesson was 4 academic hours. Along with seminars, trainings and round tables are held on a wide range of tasks of social support for clients of social service institutions. Figure 2 shows the distribution of survey participants by control instruments in training programs for social service volunteers. 


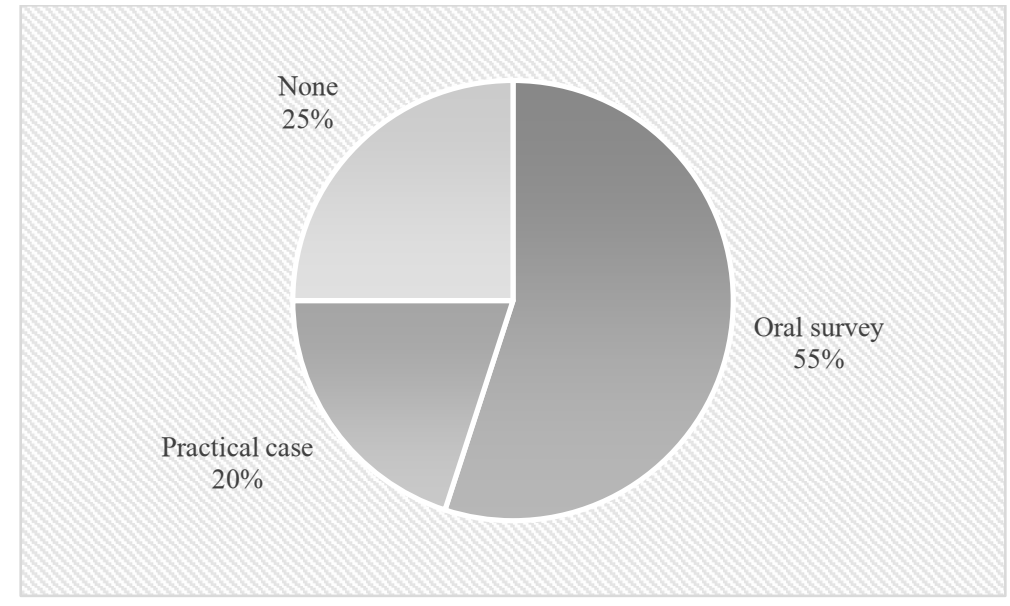

Fig. 2. Distribution of survey participants by control tools in training programs for social service volunteers, $\%$.

The final control of the results of training social service volunteers is most often carried out in the form of an oral survey, the performance of work under the supervision of a specialist is assessed in $20 \%$ of cases and in $25 \%$ the results of training are not assessed. In addition, regular monitoring of the satisfaction of service recipients and specialists of institutions with the activities of volunteers is carried out.

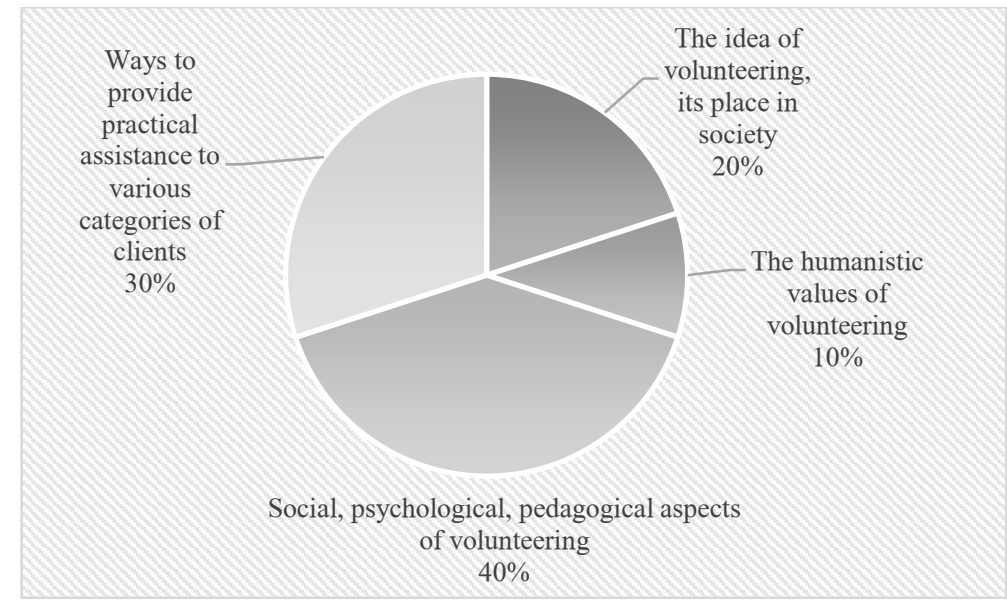

Fig. 3. Distribution of survey participants by the content of attended training programs for social service volunteers, \%.

It should be noted that the content of training programs for volunteers in the field of social services in most cases covers the applied aspects of volunteering: in $40 \%$ of cases the content of the program is devoted to the social, psychological and pedagogical aspects of volunteering, in $30 \%$ of cases it covers various ways of practical assistance to various categories of clients ... As a result of passing the programs, one can note the formation of the correct attitude towards disability, towards the characteristics of certain categories of clients, towards family members of disabled people. At the same time, about $30 \%$ of programs in terms of content are aimed at forming ideas about the goals and objectives of the volunteer movement, which contributes to solving the issues of retention of volunteers in social service 
organizations, increasing motivation for volunteering, and increasing satisfaction. Next, we will consider the assessment of the effectiveness of training according to the level of formation of the competencies of volunteer activity, Figure 4.

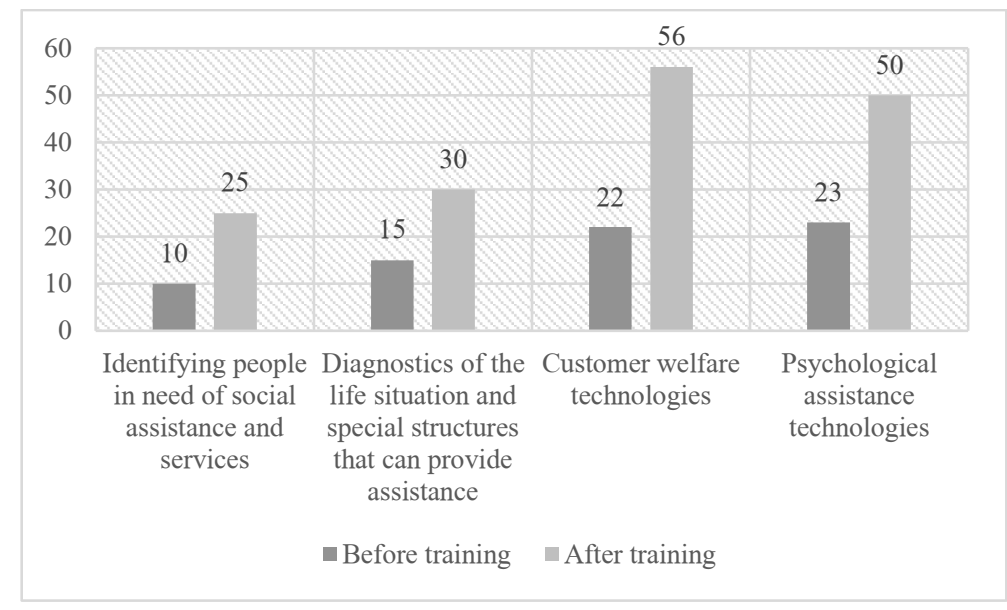

Fig. 4. Distribution of survey participants by the level of competence formation in volunteer activities, $\%$.

As one can see in the figure, the completed training allows to significantly increase the competence of volunteers in the development of technologies of social and consumer services and technologies of psychological assistance, $56 \%$ and $50 \%$ of respondents believe that the level of competence has increased in these aspects of volunteering, respectively. Only $20 \%$ and $30 \%$ of respondents, respectively, have fully mastered the issues of identifying those in need and sending them to specialized structures to receive qualified assistance. Thus, it can be concluded that it is necessary to increase the specialization of training programs for volunteers in the field of social services, as well as their subsequent profiling to work with various categories of recipients of social services.

Characterizing the training of volunteers in the field of social services, it is important to emphasize that in most cases it is carried out by specialists from institutions in which volunteer activities are carried out in the form of short-term seminars and an oral survey based on the presented material. The content components of the training cover individual methods and techniques of providing social assistance to clients of institutions. One of the essential resources of volunteer activity is attracting students of specialization areas of training for social services, who have knowledge of social services issues received in the context of training courses.

\section{Conclusions}

Analyzing the existing practice in Russia, it should be noted that at the present stage, a methodological approach is being implemented for training social service volunteers, which involves training directly at the places of providing these services with the involvement of students from specialized universities. This approach largely limits the field of application of volunteer activities, since the lack of special knowledge does not allow the provision of a number of social services. Currently, there are no regional systems for vocational training and certification of volunteers in the field of social services, the construction methodology of which is considered in the works of foreign authors. The results of the study confirmed the 
authors' hypothesis about the advisability of forming such systems in the regions of Russia. Professional training of volunteers should become one of the target priorities for the development of the volunteer movement, since the specificity of the problems of social services also requires specific knowledge, skills, and abilities. The solution to the issue of systematic training of volunteers in the field of social services should be carried out with educational and methodological support of the profiling departments of higher educational institutions with the subsequent consolidation of knowledge in the field of social work, personal care, defectology, social pedagogy in the course of practical work.

\section{References}

1. M. Deslandes, L. Rogers, Australian Journal of Adult Learning, 2 (2008)

2. J. Wilson, Annual review of sociology, 1 (2000)

3. A. R. Herzog, Achieving a productive aging society, 2 (1993)

4. S. E. Barkan, S. F. Cohn, W. H. Whitaker, Sociological Forum. Kluwer Academic Publishers-Plenum Publishers, 1 (1995)

5. D. A. Hardcastle, P. R. Powers, S. Wenocur, Community practice: Theories and skills for social workers (2004)

6. C. Cameron, P. Moss, Care work in Europe: Current understandings and future directions (2007)

7. J. Seden, Counselling skills in social work practice (2005)

8. N. I. Gorlova, Z. A. Troska, O. V. Gribkova, K. T. Zagladina, N. A. Levochkina, Revista TURISMO: Estudos e Práticas, 2 (2020)

9. A. D. Morris, S. Staggenborg, Leadership in social movements. The Blackwell companion to social movements, 1 (2004)

10. L. Hustinx, L. C. P. M. Meijs, Voluntary Sector Review, 2 (2011)

11. T. Vantilborgh, J. Bidee, R. Pepermans, J. Willems, G. Huybrechts, M. Jegers, VOLUNTAS: International Journal of Voluntary and Nonprofit Organizations, 4 (2011)

12. K. S. Rook, D. H. Sorkin, The International Journal of Aging and Human Development, 4 (2003)

13. R. Rosenthal, Human relations, 4 (1965)

14. M. A. Hager, J. L. Brudney, Challenges in volunteer management, 1 (2008)

15. E.S. Ogorodnikova, A.E. Plakhin, T.V. Kochergina, P.V. Mikhailovsky, T.I.Guseva, M.V. Selezneva, Espacios, 25 (2019) 